\title{
STARCRAFT II: gestos, posturas e expressões faciais como oportunidade para pensar a experiência do usuário em games
}

\author{
Osvaldo Relder Araújo da Silva \\ Faculdade Fucapi \\ relderdesigner@gmail.com \\ Alexandre Santos de Oliveira \\ Faculdade Fucapi \\ olialx@gmail.com
}

\begin{abstract}
Resumo: A presente pesquisa teve como objetivo, analisar os gestos, as posturas e expressões faciais de um jogador, durante três partidas do jogo de estratégia Starcraft II. A metodologia de abordagem qualitativa, foi desenvolvida por meio das etapas de pré-experimento, experimento e pós-experimento. Utilizanido como referências os conceitos do corpo, sinestesia e experiência do usuário, os resultados obtidos indicaram a necessidade de considerar o processo de projetação dos games a partir da ideia de sistema cultural que considere as formas de como o usuário reconstrói o universo dos games.
\end{abstract}

Palavras-chave: Design de jogos, Cultura, Sinestesia, Stracraft II, Experiência do usuário.

\begin{abstract}
The present study aimed to analyze the gestures, postures and facial expressions of a player for three matches of the Starcraft II strategy game. The methodology of a qualitative approach was developed through the stages of pre-trial, trial and post-trial. Using as references the concepts of the body, synesthesia and user experience, the results indicate the need to consider the process of projecting the games from the idea of cultural system that considers the ways how the user reconstructs the world of games.
\end{abstract}

Keywords: Game design Culture, Synesthesia, Stracraft II, User Experience. 


\section{INTRODUÇÃO}

Este trabalho visa apresentar os resultados da pesquisa desenvolvida no âmbito do Programa de Pós-graduação lato sensu em Design, Comunicação e Multimídia na Faculdade Fucapi, Manaus-AM. A pesquisa levada a efeito teve como objetivo, analisar gestos, posturas e expressões faciais de um jogador, durante três partidas do jogo de estratégia Starcraft II, utilizando como referenciais os conceitos do corpo, sinestesia e experiência do usuário, com vistas a avaliar as ações realizadas pelo usuário ante o jogo, procurando identificar, durante a partida, os elementos que permitem indicar os níveis de envolvimento do jogador em relação ao jogo.

O Starcraft // é um jogo de estratégia e ficção científica criada pela Blizzard Entertaiment, empresa situada nos Estados Unidos. O jogo decorre da continuação direta do Starcraft I e Starcraft Brood War, que é um pacote de expansão ${ }^{1}$. O desenvolvimento desta nova versão foi anunciado em 2003, após treze anos desde o lançamento da primeira versão do jogo. Em 27 de julho de 2010, a nova versão é lançada simultaneamente em diversos países, inclusive no Brasil. O Jogo possui três raças, Protoss, Terrano (conhecido como "Terran" nas primeiras versões) e Zerg. 0 foco do Starcraft II é o mundo multiplayer ${ }^{2}$ contudo, o jogo possui também um mundo singleplayer ${ }^{3}$.

Em muitos trabalhos e pesquisas desenvolvidas sobre o tema do Game Design, geralmente o foco gira em torno da interface, do roteiro, da jogabilidade, ou mesmo do jogo em si e pouca atenção tem sido dada ao usuário. Talvez a abordagem funcional do design de games e a necessidade de aperfeiçoamentos que contribuam para a geração de sistemas em que padrões de cores, elementos gráficos tridimensionais e informações textuais, organizadas de forma harmônica, estimulem a pesquisa e o desenvolvimento focados nas características objetivas e racionais de diversos aspectos relacionados ao uso desta classe de produto.

Uma observação exploratória e assistemática indicou, num primeiro momento, que o jogo Starcraft /I oportuniza aos jogadores uma série de experiências que ultrapassam os limites da relação usuário-interface e, tomando como base um referencial teórico específico ligado ao corpo, à sinestesia e a experiência do usuário, optou-se por investigar que contribuições uma análise das posturas, movimentações corporais e expressões faciais de um jogador, exposto a um jogo de estratégia, pode trazer para o campo do Game Design.

Para dar conta do problema, o procedimento metodológico iniciou-se com a seleção do perfil do jogador que participaria da pesquisa, organização da data e preparação do ambiente, caracterizando o pré-experimento. Numa segunda etapa, buscou-se a captação de informações envolvendo o jogador e o jogo, considerando no processo o experimento, cujo a obtenção dos dados foram feitas por meio de filmagens e observações com caderno de campo. E por fim o pós-experimento que é o tratamento dos dados e análises para gerar a discussão da pesquisa.

Assim, o presente trabalho está estruturado em três blocos. No primeiro são apresentados os elementos da fundamentação teórica e que tomaram o corpo, a

\footnotetext{
${ }^{1}$ É uma adição a um jogo eletrônico já existente. Estas adições geralmente agregam novas áreas de jogo, armas, objetos, modos de jogo, minigames e/ou enredo estendido de um jogo já completo e lançado.

${ }^{2}$ São jogos que permitem que vários jogadores participem simultaneamente de uma mesma partida

${ }^{3}$ Modo que permite o jogador a participar de partidas individuais contra há máquina. 0 jogador pode controlar apenas um personagem e se houve outros personagens do seu lado é o computador que controla.
} 
sinestesia e a experiência do usuário como categorias de base. No segundo bloco, são apresentados os resultados obtidos nas etapas de pré-experimento e experimento, a partir da organização dos dados empíricos coletados e no terceiro bloco, são apresentados os elementos da discussão contendo as principais conclusões e as oportunidades para futuros estudos.

\section{FUNDAMENTAÇÃO TEÓRICA}

Passaremos a conceituar as categorias corpo, sinestesia e experiência do usuário, tomadas como base para reflexão e condução das análises dos dados obtidos de um jogador exposto a um jogo de estratégia, o Starcraft II.

\subsection{Corpo}

Segundo Le Breton (1995, pág. 29), as representações sociais apontam para diversas formas de comportamento, dentro de inúmeros simbolismos existentes numa sociedade e servem para guiar as diferentes relações explícitas que atingem o interior do corpo. Essas formas de representação são contornos de conhecimentos envolvidos por um estado social numa visão global. Em síntese, o corpo é um elemento insolúvel do homem, que procura sempre uma cultura social e funciona com um limite de alcance de outros com a presença do sujeito.

Do ponto de vista de Rector \& Trinta (1999, pág. 61-62), a principal qualidade humana para interação do corpo com a sociedade é o gesto, que pode ser distribuído em quatro categorias: 1) Emblemáticos: são usados de forma intencional, o emissor tem consciência do uso dele, são simbólicos e conhecidos por todos numa sociedade. 2) Ilustradores: acompanham a fala, enfatizam uma palavra ou frase. 3) Reguladores: alimentam a comunicação entre dois ou mais interlocutores. 4) Adaptadores: são gestos difíceis de definir pois, decorrem de situações que exigem adaptação desde a infância do indivíduo.

Os autores ainda afirmam que a formação de uma imagem social requer consciência e controle de gestos e posturas. A expressão por meio dos gestos serve tanto como intenção cognitiva, expressiva ou descritiva, quanto à alusão de ordem afetiva. Assim, o gesto e as posturas são ações corporais visíveis pelo significado que é transmitido, por meio de uma expressão voluntária.

\subsection{Sinestesia}

O que estimula o corpo a interagir com o mundo? Certamente seria muita audácia afirmar que a sinestesia contribui para o todo, mas é quase possível assegurar que ela coopera de forma generosa. Segundo Oliveira (2011, pág. 47) a sinestesia refere-se a uma sensação que segue uma percepção. Trata-se de um fenômeno neurológico ocasionado por um estímulo em um determinado sentido que acaba por desencadear outras formas de resposta diferentes daquelas esperadas.

O autor destaca que após um período de esquecimento e preconceito o estudo da sinestesia volta interessar as ciências, isto por conta do desenvolvimento da neurociência e em particular da neuropsicologia. Por outro lado, Basbaum (2012, pág. 246) aponta que a origem da sinestesia surge do grego "syn" que significa "simultâneas" e "aesthesis" que significa "sensações" e forma o conceito, "sensações simultâneas" ou seja, indivíduos expostos a um estímulo relacionado a uma atividade sensorial, sentem sensações em uma modalidade diversa. 
Assim, pensar na sinestesia consiste em perceber os sentidos de forma integrada, A capacidade de expressão que cada um deles oferece para a manifestação de ideias, emoções, sentimentos e desejos é o que caracteriza o comportamento das sociedades e da cultura de forma ampla e específica. Através dos sentidos, que são tanto a porta de entrada como a porta de saída, o homem interpreta o mundo, fala de si, ao mesmo tempo que fala dos outros e para os outros sendo, desta forma, um lugar a ser considerado nos processos de análise que envolvem jogos e jogadores no âmbito do game design.

\subsection{Experiência do usuário/jogador em games}

A Experiência do usuário, segundo Savi (et al 2010, pág. 04), é um termo que nasceu do inglês User Experience (UX), que abarca a satisfação de uma pessoa em relação à utilização de um determinado sistema ou serviço. A experiência do usuário pode ser vista nas experiências significativas das interações humanas e, além disso, abrange as percepções de uma pessoa dos aspectos práticos, tais como o proveito, a facilidade de uso e a eficiência da interface.

O autor ainda afirma que a natureza da experiência do usuário é subjetiva, pois consiste, num primeiro momento, na percepção e reflexão do indivíduo antes, durante e após o contato interfacial. A experiência do usuário é ativa e constantemente modificada ao longo do tempo, devido à evolução das circunstâncias, inovações e tendências. No que respeita aos games há uma expectativa de que a utilização de jogos lance experiências positivas onde os jogadores possam interagir com os artefatos, envolvendo-se e aprofundando-se no ambiente do jogo, e isso vem seguido de interações e imersões - que são de grande relevância para a análise e projetação de jogos.

Com relação à experiência do usuário/jogador em games, é possível compreender que se trata de uma experiência de interação com os jogadores, com a interface e os periféricos do game e com aquele que joga, ou seja, o próprio jogador. Neste sentido, aparece a necessidade de um investimento maior na compreensão de como ocorrem estes processos, tanto com a finalidade de melhor compreender a experiência do usuário com os games, como aperfeiçoar as interfaces e talvez, contribuir também com o aprimoramento dos periféricos que funcionam como mecanismos de mediação da experiência.

\section{RESULTADOS}

Para Bauer e Gaskell (2002, pág. 20), o objetivo da análise é procurar sentido e compreensão, constituir dados, mas a análise deve ir além da aceitação deste valor aparente. Em termos práticos, a análise e interpretação exigem tempo e esforço. $\mathrm{Na}$ essência elas implicam na imersão do próprio pesquisador e incluem: marcar e realçar, acrescentando notas e comentários ao texto, bem como recortar e reinterpretar se necessário.

Por outro lado Marconi e Lakatos (2003, pág.231) destacam que esta etapa é o momento de transcrever os resultados, sob forma de evidências para confirmar ou negar as hipóteses, levando em consideração a generalização dos resultados para o universo, no que se refere aos objetivos determinados. No caso deste pesquisa a 
análise dos resultados foi produzida a partir das etapas de desenvolvimento da pesquisa a saber, as partidas de Starcraft II.

\subsection{A primeira partida}

O que percebemos na primeira partida foi que o jogador principal desenvolveu uma série de comportamentos. Ele começa com certa concentração, mas com o passar do tempo é possível perceber menos tensão e mais determinação e no fim, observa-se a descontração com a vitória. Tal processo acarreta diversas mudanças de posturas, realização de gestos e diferentes expressões faciais que, nesse caso, destacam-se por serem mais percebidas que as demais, a Figura 1 , mostra um panorama ilustrado da primeira partida.

O processo comportamental mencionado anteriormente é baseado em posturas, gestos e expressões faciais, que são "sensações simultâneas" apresentadas por Basbaum (2012, pág. 246) que é exatamente a situação na qual o indivíduo é exposto a um ou mais estímulos, que estão relacionados a uma atividade sensorial. No nosso contexto, o jogador principal está exposto a uma partida on-line', em um jogo de computador.

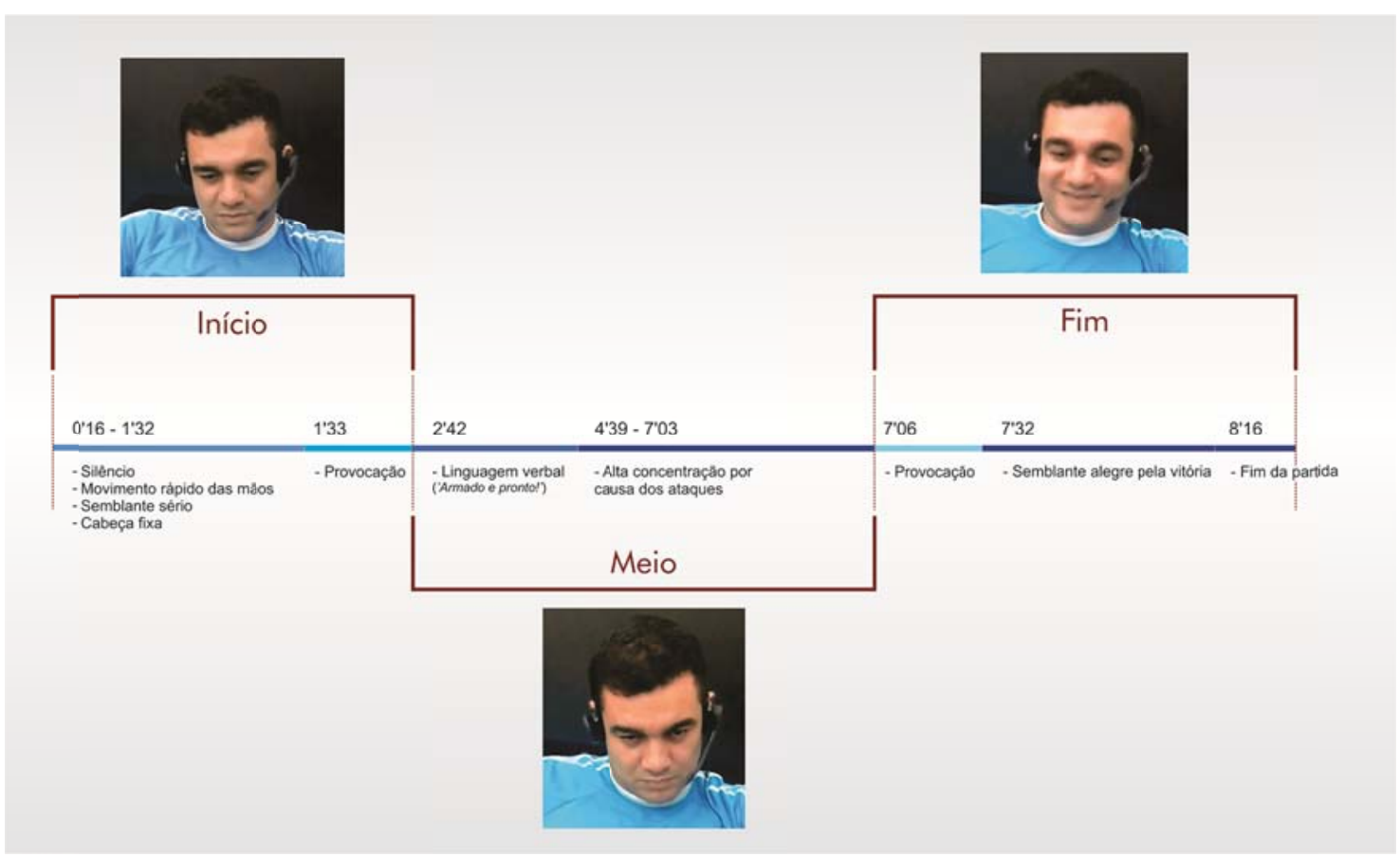

Figura 1 - Panorama da primeira partida de Starcraft II.

Fonte: Elaborado pelo autor, com base na pesquisa realizada.

\subsection{A segunda partida}

A segunda partida teve um tempo maior de jogo em relação à primeira contudo, o processo comportamental do jogador principal aumentou, apresentando resultados similares à primeira partida onde observamos mais mudanças de posturas do que gestos e expressões faciais. Assim, foi possível perceber que, com a adaptação demonstrada pelo jogador principal, frente às câmera, os estímulos sinestésicos foram percebidos mais detalhadamente, de forma foi possível observar um maior envolvimento na partida, evidenciado pelo comportamento do jogador, que pode ser observado, de forma sintética, na Figura 2. 
Na segunda partida notamos em caráter aplicado o conceito de Ferreira (2008, pág. 02), pois o maior envolvimento é a imersão do jogador principal na partida como um todo. A ideia de imersão permitiu entender que o jogador proporciona para si o prazer e a satisfação, através da experiência com o jogo, que sobretudo o "convida" a adentrar na realidade ilusória criada.

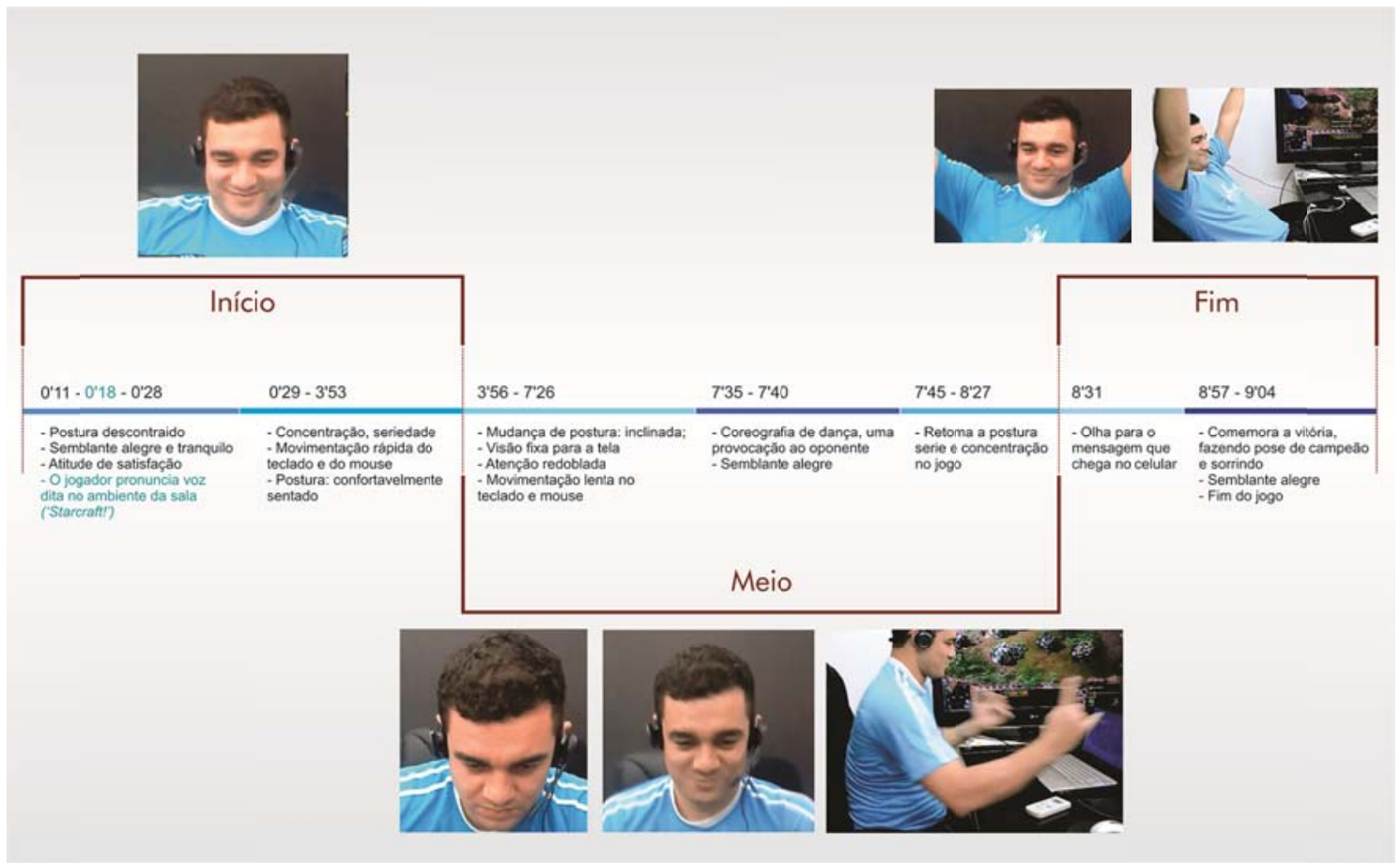

Figura 2 - Panorama da segunda partida de Starcraft II.

Fonte: Elaborado pelo autor, com base na pesquisa realizada.

\subsection{A terceira partida}

Aqui o jogador principal, decidiu diferenciar e escolheu a raça Terrano, uma raça que ele não tinha costume de jogar. O tempo de jogo desta "partida" foi o menor entre todas, $4 \mathrm{mim}$ 54s. Por estar jogando com uma raça diferente, foi possível observar uma dificuldade em manipular os comandos do teclado. Ele jogava de forma defensiva porém, notou-se uma nova experiência, mesmo jogando com uma raça fora do costume de jogo.

O jogador adversário manteve a mesma raça (Terrano) desde a primeira partida. Nessa partida o jogador principal aparentou estar muito confiante, em Omim $08 \mathrm{~s}$ à $1 \mathrm{mim} 26 \mathrm{~s}$ várias expressões faciais acontecem, inicia com sorriso, em seguida descontração, concentração, atenção e provocações. No período de $1 \mathrm{mim} 27 \mathrm{~s}$ à $3 \mathrm{mim}$ $56 \mathrm{~s}$, o jogador principal expressa tranquilidade e pouca concentração, faz poucos movimentos com as mãos no mouse e teclado e alguns movimentos com a boca. Ele está sentado de forma confortável e apresenta pouca movimentação do corpo. Já em 3 mim 58 s até 4 mim $02 \mathrm{~s}$, demonstra expressões negativas, sorrisos "sem graça" e sussurra em voz baixa expressões que não conseguimos captar, nesse momento ele estava em desvantagem na partida.

No tempo $4 \mathrm{mim} 04 \mathrm{~s}$ até $4 \mathrm{mim} 27 \mathrm{~s}$, o jogador apresenta uma expressão séria e tenta alguma reação na partida, para tirar a desvantagem, mas em $4 \mathrm{mim} 30$ s à $4 \mathrm{mim}$ 44s ele sorri e coça a cabeça, ao fundo, ouve-se o jogador secundário gargalhando e provocando. Em 4mim 46s o jogador principal abandona a partida, convicto da derrota 
e em 4 mim 48 s à $4 \mathrm{mim} 54 \mathrm{~s}$ bate na mesa e lamenta, a partida acaba. A Figura 3 apresenta, sinteticamente, o panorama da partida.

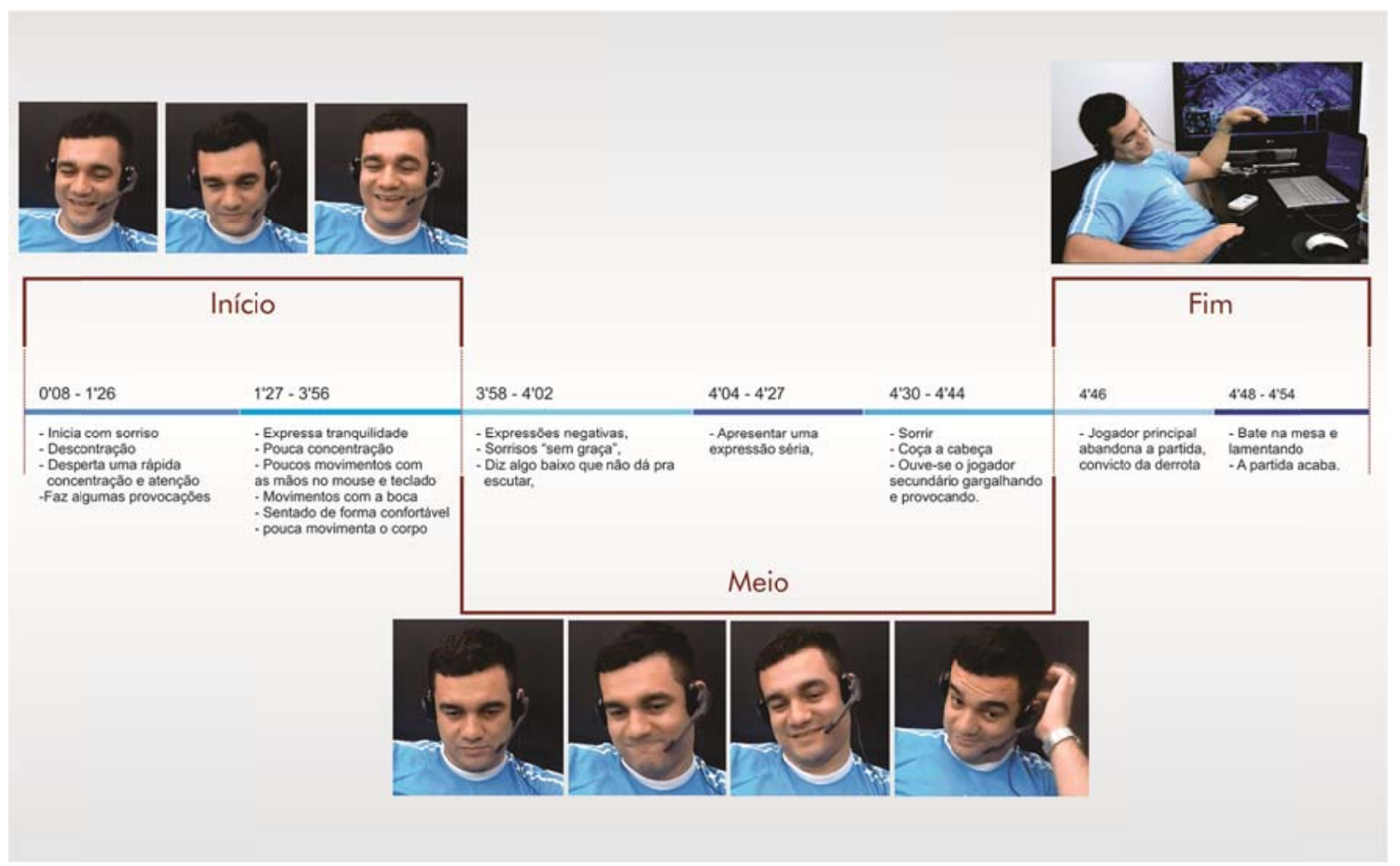

Figura 3 - Panorama da terceira partida de Starcraft II.

Fonte: Elaborado pelo autor, com base na pesquisa realizada.

A terceira e última partida apresentou um tempo menor entre todas as outras, e foi relevante para a pesquisa pois nela, houve uma mudança na experiência do jogador principal escolhendo outra raça para jogar e o resultado apresentado é que as expressões se destacaram mais do que os gestos e posturas. Porém, os gestos também são notados, uma vez que a falta de experiência ao jogar cim uma raça que não tinha costume de jogar, fez com que o jogador principal realizasse movimentos rápidos em busca de melhor e maior eficiência.

Percebemos aqui o conceito de Le Breton (1995, pág. 29), sobre as manifestações sociais que são identificadas pelas expressões do jogador principal, ele coloca inúmeros simbolismos que são existentes numa sociedade e servem para guiar as diferentes relações do corpo. São formas de representação de conhecimentos, entrelaçados por uma conjuntura social observáveis a partir de uma visão global.

\section{DISCUSSÃO}

A discussão gerada sobre a pesquisa indica que, em processos de avaliação de jogos, é necessário levar em consideração a experiência do usuário. A interface, a jogabilidade, o roteiro são importantes mas, faz-se necessário empreender e desenvolver metodologias que permitam avaliar de forma mais direta a experiência do usuário diante do jogo, através dos sinais e indícios expressos em sula corporeidade. Surge também a necessidade de pensar os jogos sob uma perspectiva sinestésica, objetivando considerar como o usuário se comporta diante de determinados estímulos, face as ações que vão sendo desenvolvidas durante o jogo.

Ao analisar as posturas, gestos e expressões faciais, foi possível observar na primeira partida mais expressões do jogador, talvez por estar "incomodado" frente às 
câmeras que o rodeavam e principalmente, por que as ações que ocorrem na partida, fazem, naturalmente, esse tipo de reação corporal acontecer. Este fato é comprovado por Rector \& Trinta (1999, pág. 21), que afirmam: "o homem por se mover constantemente, colocando em atividades todas as suas formas de expressões" produzem reações diante dos diferentes fatos e circunstâncias que tem diante de si.

Na segunda partida, apesar de o tempo ser maior, o resultado foi diferente da primeira, até porque houve uma adaptação por parte do jogador principal em relação às câmeras. Ele já não se importava e manteve o foco na partida e foi esse foco que fez com que o corpo reagisse diferentemente da partida anterior, dando mais condição da emergência de outras posturas, expressão faciais e gestos.

Analisando a terceira partida, o diferencial dela é que o jogador principal, jogou com uma raça que não era a de costume. Tal escolha implicou na duração da partida que foi a mais curta de todas. As expressões faciais e os gestos foram os destaques pois, foi possível perceber uma certa tensão para alcançar a mesma eficácia de quando o jogador principal estava jogando com a raça de costume.

Por outro lado, após a realização do experimento, observamos que durante as filmagens o jogador fica sentando, então os movimentos corporais são do abdômen para cima, dificultando um conjunto maior de percepções sobre posturas e gestos.

No entanto, a pesquisa indicou a possibilidade de análise sinestésica das posturas de um jogador, visíveis por meio do corpo e das ações ocasionadas no jogo. Sendo elas positivas ou negativas, sempre garantem razões e anseios para o jogador, anseios que estimulam movimentos corporais, expressões faciais e gestos como um todo. Assim as ações (gestos, posturas e expressões faciais) que foram manifestas pelo jogador, não foram preparadas ou de todo previstas pelo desenvolvedor do jogo, mas manifestadas sinestesicamente pelo próprio jogador que criou cenários, realidades, sensações e emoções usando o corpo para demonstra-las, ou seja, constituindo a experiência do usuário. A Figura 4 abaixo mostra um esquema gerado com o resultado do processo de análise.

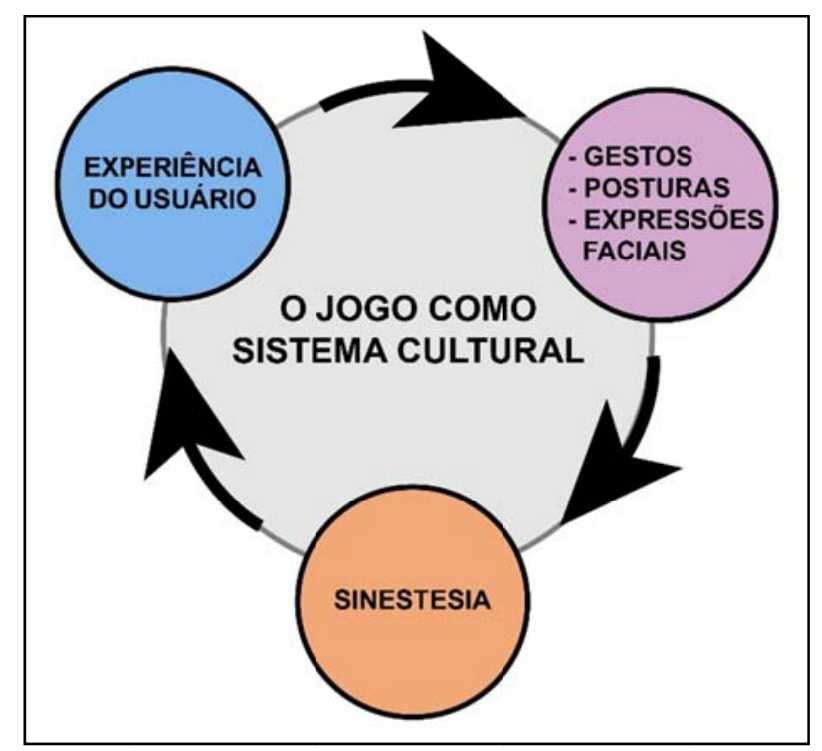

Figura 4 - Esquema baseado no corpo, experiência do usuário e sinestesia. Fonte: Elaborado pelo autor, com base na pesquisa realizada. 
A figura indica ainda, de forma sintética, a inter-relação entre gestos, posturas e expressões faciais como indicativas das relações sinestésicas entre o usuário e o jogo. Coloca o desafio de trazer para a discussão e investigação sobre a experiência do usuário em games, estas dimensões como locais de comunicação entre o jogador e o jogo. A relação com o jogo cria uma nova forma de comunicação entre o jogador e o seu mundo exterior pois, uma série de gestos, posturas e expressões faciais não calculadas, não previstas pelo game design são produzidas pelo jogador.

Desta forma o campo do game apresenta-se como um novo sistema cultural composto de vários subsistemas que transcendem a interface, os periféricos e o próprio jogador. O jogo, visto sob o ponto de vista de um novo sistema cultural, desencadeia, uma série de posturas, gestos e expressões faciais imprevisíveis e que são acionadas de uma forma sinestésica e que ocorre de acordo com o processo de desenvolvimento do jogo, um desenvolvimento imprevisível. Trata-se de um sistema cultural também porque aciona um conjunto de atores (jogadores, observadores, administradores de sistema, projetistas, pesquisadores, dentre outros) que compõem um determinado ecossistema cultural próprio, construído a partir de uma relação sinestésica entre os elementos constituintes do sistema cultural dos games.

A pesquisa indicou ainda que, pensar o desenvolvimento de jogos levando em consideração além da dimensão projetual da interface, sua navegação ou mesmo os dispositivos externos, os periféricos, apresenta uma dupla oportunidade, a primeira é a possibilidade de aperfeiçoamento das interfaces e das relações do jogador com o jogo e a segunda, coloca os jogos como elemento da cultura, como desencadeador de experiências que vão para além do jogo, rompendo com a previsibilidade presente na ideia de que as ações manifestas pelo jogador são totalmente previsíveis.

Por meio da sinestesia, que o jogo proporciona, é possível observar que ele deixa de ser um produto participante de uma cadeia previsível indicando a possibilidade de desencadear outras formas de expressão e outras experiências, para além daquelas previstas pelo game designer. Esta constatação enriquece nossa percepção sobre a importância de estudos desta natureza, ao tempo que cria as oportunidades para pensar o game como produtor de cultura. Apresenta ainda oportunidades para o estudo da presença do corpo no mesmo, bem como de games cada vez mais sinestésicos e imersivos, constituindo estas temáticas oportunidades para pesquisas futuras no que respeita à experiência do usuário em games.

Verificamos também a chance de avaliar os jogos sob o ponto de vista do usuário, mesmo sendo um usuário experiente. As sugestões que ficam para futuras pesquisas residem na urgência em, cada vez mais, considerar o jogador e não somente as interfaces ou o próprio jogo no processo de projetação de games. Talvez como primeira sugestão de pesquisa, seria uma boa ideia fazer experimentos com usuários sem habilidade em determinado jogo. Então, outras duas sugestões que ficam é analisar se há algum resultado diferente do que foi apresentado, em relação à faixa etária e por níveis socioeconômicos. Sugerimos ainda que a avaliação da experiência do usuário em outros tipos de jogos que utilizam periféricos, tais como joysticks, sensores que fazem leitura do corpo como o Kinect, acessórios que auxiliam na movimentação, tais como como os controles do Nintendo Wii e o Move do Playstation, além dos jogos musicais como Guitar Hero, Rockband e afins. 


\section{REFERÊNCIAS}

BASBAUM, Sergio. Sinestesia e percepção digital. 2012. Disponível em: http://www4.pucsp.br/pos/tidd/teccogs/artigos/2012/edicao_6/9-

sinestesia_e_percepcao_digital-sergio_basbaum.pdf Consultado em: 08/11/2013.

BAUER, Martin W. GASKELL, George. Pesquisa qualitativa com texto, imagem e som Um manual prático. Editora Vozes, 8ㅇ Edição 2002.

BULHÕES, B., ALVES, B. e R. DUBIELA. Framework CDE: Com foco na experiência do usuário de jogos digitais. 2010.2 Disponível em: http://sbgames.org/papers/sbgames10/artanddesign/Full_A\&D_7.pdf Consultado em 22/12/2013.

FERREIRA, Emmanoel. Games e Imersão: A realidade híbrida como meio de imanência virtual. 2008, consultado em: 05/02/2014 disponível em: https://www.academia.edu/529960/Games_e_imersao_a_realidade_hibrida_como_m eio_de_imanencia_virtual.

LE BRETON, David. Antropologia del cuerpo y modernidade. Ediciones Nueva Visión.1995.

MARCONI, Marina de Andrade. LAKATOS, Eva Maria. Fundamentos de metodologia científica. 5o ed. - São Paulo. Atlas 2003.

NETO, Felix de Souza. ALVES, Lynn. Jogos Digitais e Aprendizagem: um estudo de caso sobre a influência do design de interface. 2010. Disponível em: http://sbgames.org/papers/sbgames10/artanddesign/Full_A\&D_15.pdf Consultado em: 22/12/2013.

OLIVEIRA. Alexandre de. Cultura, Sinestesia e o Ensino do Design no Amazonas. São Paulo: Scortecci/Fucapi, 2011.

RECTOR \& TRINTA, Monica, Aluizio Ramos. Comunicação do corpo. Editora Ática. 4은 Edição. 1999.

SALEN, Katie. ZIMMERMAN, Eric. Rules of Play: Game Design Fundamentals. Massachusetts. The MIT Press, 2004.

SAVI, Rafael. VON WANGENHEIM, Christiane Gresse. ULBRICHT, Vania. VANZIN Tarcisio. Proposta de um Modelo de Avaliação de Jogos Educacionais. 2010. Consultado em: 27/12/2013. Disponível em: http://seer.ufrgs.br/renote/article/viewFile/18043/10630.

VIEIRA, Luigi. Experiência do Usuário, Avaliação e Jogos Eletrônicos, 2012. Disponível em: http://game2nextlevel.wordpress.com/2012/06/15/experiencia-do-usuarioavaliacao-e-jogos-eletronicos/ Consultado em: 22/12/13. 